\title{
Conditions for Minimum Dynamic Loading of Multi-brake Hoists
}

\author{
Khoreshok Alexey A. ${ }^{\mathrm{a}}$, Tyulenev Maxim A. ${ }^{\mathrm{b}}$ \\ T. F. Gorbachev Kuzbass State Technical University, \\ Kemerovo, Russian Federation \\ ahaa.omit@kuzstu.ru, b tma.geolog@kuzstu.ru
}

\begin{abstract}
Hoists are equipment with unsteady service. Due to this, there is a considerable dynamic loading on the hoist and its elements, sometimes involving failure of equipment. On the other hand, technological development is going on. Modern control elements are widely used to realize economic and comfortable driving behavior. In this work the review is given of using modern technology with regard to reducing loads on crucial components of the hoist in order to prolong lifetime or to get a more economic design. The article presents the calculations in order to optimize the load of the hoists (lifting machines) proposed for different modes of their use. These calculations can be used to construct the braking hoisting units of a new design.
\end{abstract}

Keywords - Hoists; torque; dynamic; safety brakes.

\section{INTRODUCTION}

Matters of mining equipment reliability are increasing with particular importance due to the strengthened tendency of growth of volumes of coal mined in Kuzbass (Western Siberia, Russia) [1-3]. Today they are the object of primary attention of the Government [4-5] as the matter of labor security and safety [6-7] as well as tightening of the requirements for the owners of the coal companies [8].

Hoists are mechanical systems with different spots of load introduction $[9,10]$. They are used in all sectors of the mining industry - both underground [11, 12] and in open cast [13] mining, also it's an important element of the work safety [14, $15]$.

\section{MATERIALS AND METHODS}

The load itself, motors and brakes introduce forces and torques, all differing over time. Due to these variations the elements of the hoist are exposed to dynamic internal forces. An example is the torque in the gearing input shaft during a braking process out of hoisting of the load (Figure 1). Tremendous torque peaks occur, e.g. as result of the change

\author{
Vöth Stefan \\ Technische Fachhochschule Georg Agricola für \\ Rohstoff, Energie und Umwelt zu Bochum \\ Bochum, Germany \\ Voeth@tfh-bochum.de
}

from hoisting to braking and the peak involved with this change of condition. EN 13001-2 proposes dynamic factor of up to $\phi 5=3,0$ for systems with significant clearance [16]. It would be of advantage to reduce or even to remove such loading peaks. Following conditions for minimum dynamic loading of hoist elements are shown.

This is a text with more detailed information to publication [17]. Definitions of the used qualities static load torque Mst*, load factor LF, mass factor MF and braking factors BFHB and BFSB are introduced there.

Static load torque Mst*:

$$
M_{s t}^{*}=\frac{m_{S W L} \cdot g \cdot r}{i_{G} \cdot i_{S}} .
$$

Load factor LF:

$$
L F=\frac{m}{m_{S W L}} .
$$

Mass factor MF:

$M F=\frac{\theta_{1}}{\theta^{*}+L F \cdot m^{*}}$.

Braking factor BFHB:

$$
B F_{H B}=\frac{M_{H B}}{M_{s t}^{*}} .
$$

Braking factor BFSB:

$$
B F_{S B}=\frac{M_{S B}{ }^{*}}{M_{s t}{ }^{*}} .
$$




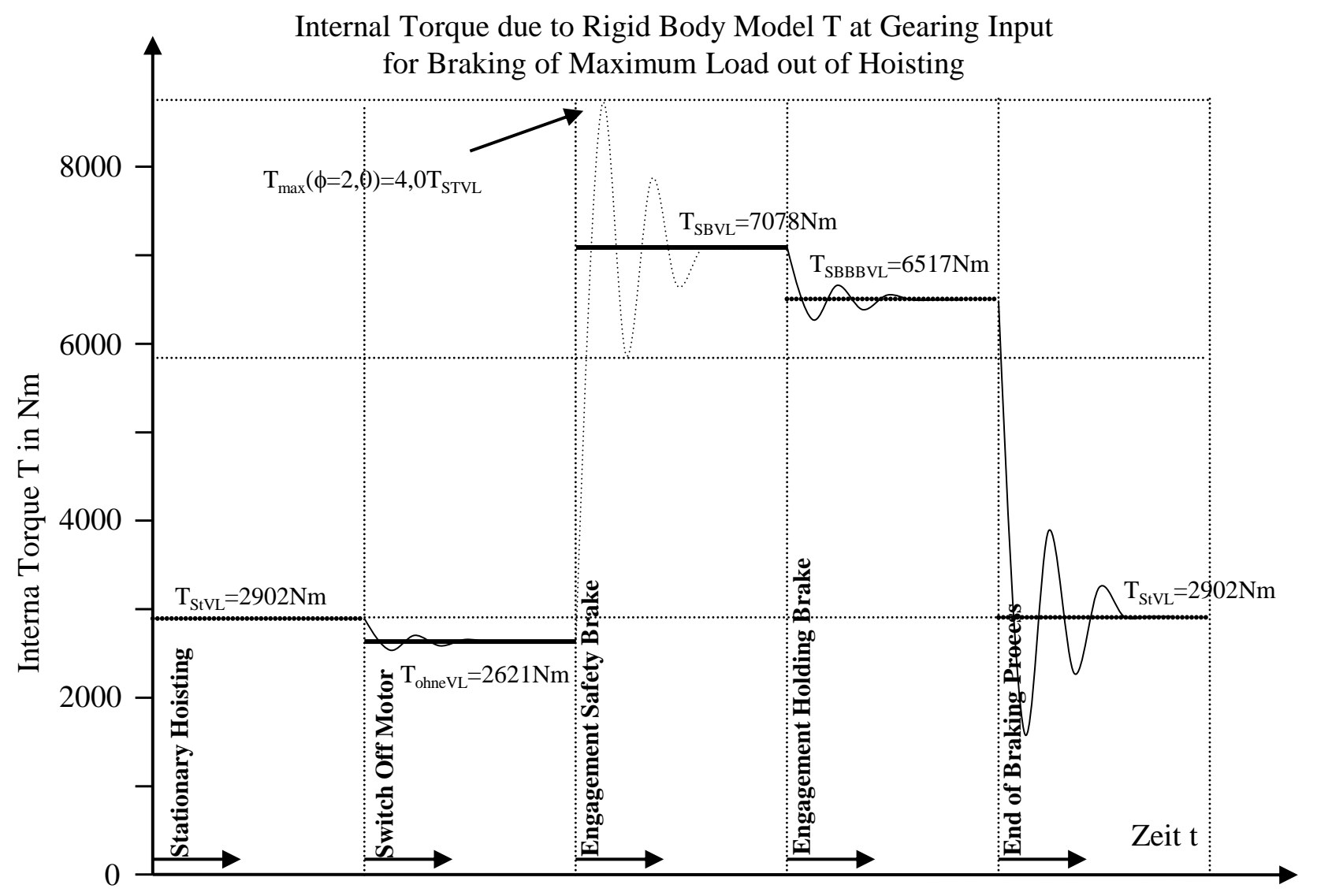

Figure 1: Dynamic torque in input shaft of gearing hoist during braking out of hoisting

Typical quantities are load factor $\mathrm{LF}=0.1 \ldots 1.0$, mass factor $\mathrm{MF}=0.8 \ldots 0.95$ and brake factor $\mathrm{BFSB}=1.7 \ldots 2.2$.

\section{DISCUSSION}

For a closer look on the behaviour a loss-free, partly redundant hoist with safety brakes is considered (Figure 2).

Central element of the hoist is the gearing. The load is suspended by a load attachment device and a rope drive with
$8 / 2$ reeving. Both ropes are running onto a drum each, which are coupled with the gearing output shafts. On the board disc of each rope drum a safety brake is located. The hoist is driven by two motors which are connected to the gearing input shafts. On the motor shafts axis a service brake is located each. 


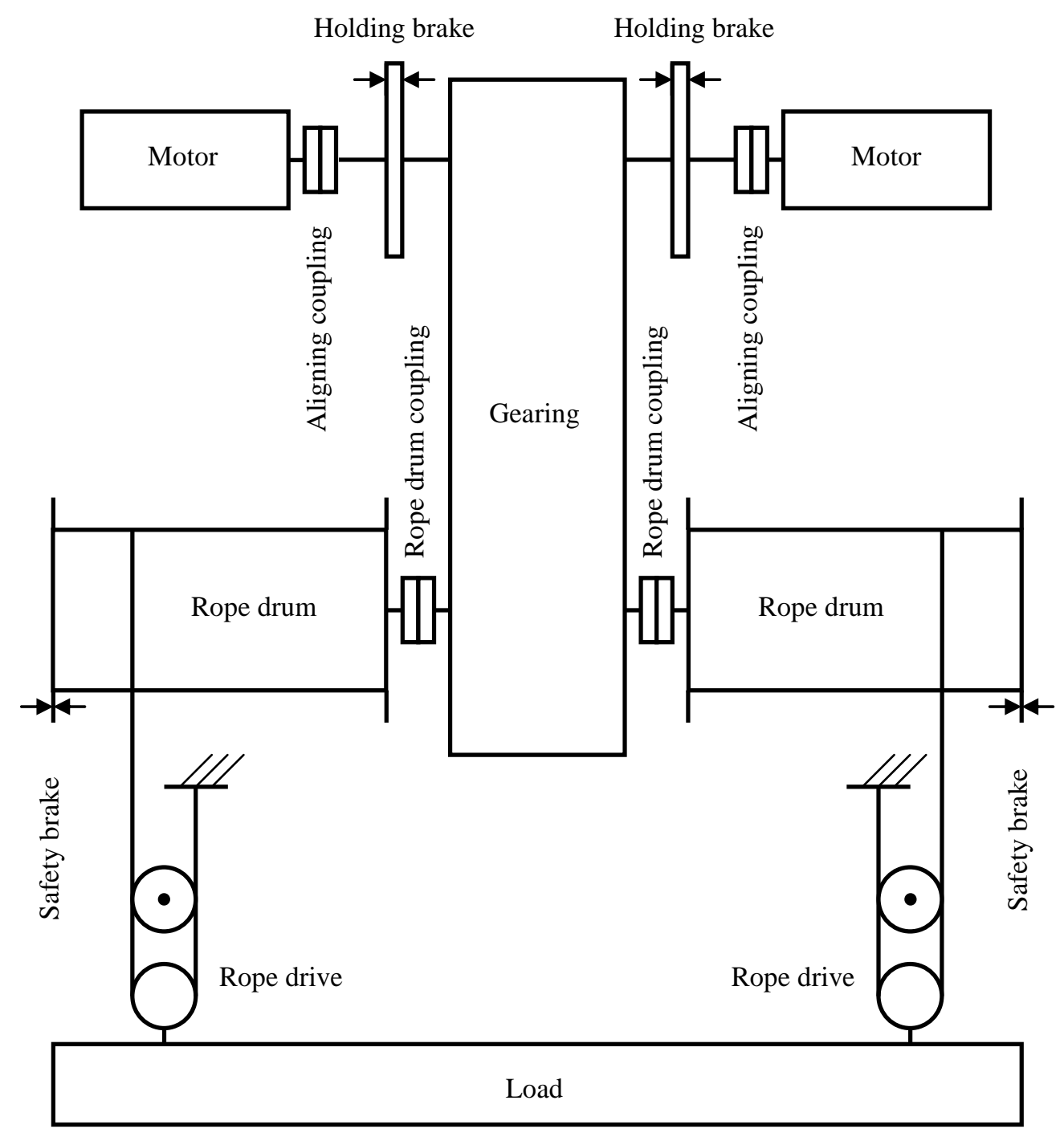

Figure 2: Reference system

The reference hoist is described by the following data:

Motor speed

Hoisting speed

$\mathrm{n} 1=1500$ min -1

$\mathrm{vH}=45 \mathrm{~m} / \mathrm{min}$

Mass, motor shaft

$\theta 1=20 \mathrm{kgm} 2$

Mass, rope drum shaft

$\theta 2=500 \mathrm{kgm} 2$

Mass, load attachment device

Mass SWL

$\mathrm{mLAM}=10 \mathrm{t}$

Radius, rope drum

$\mathrm{mSWL}=52 \mathrm{t}$

Gearing ratio

$\mathrm{r}=0.5 \mathrm{~m}$

Rope drive ratio
$\mathrm{iG}=26.2$

$\mathrm{iS}=4$
Service brake torque

Dead time service brake

Safety brake torque

Dead time safety brake

Gearing stiffness

Clearance drum coupling

$$
\begin{aligned}
& \mathrm{MBB}=5.8 \mathrm{kNm} \\
& \text { totoB }=0.4 \mathrm{~s} \\
& \mathrm{MSB}=130 \mathrm{kNm} \\
& \text { ttotSB }=0.1 \mathrm{~s} \\
& \mathrm{c}=4 \times 104 \mathrm{Nm} / \mathrm{rad} \\
& \mathrm{s}=3^{\circ}
\end{aligned}
$$

The hoist with given data is regarded as a rigid mass model with definitions according to Figure 3. Three masses are defined: One rotating mass at each end of the gearing and a translational mass to model load plus load attachment device. Positive direction of movement is lifting. Braking torques are defined positive for positive movement, lifting. 


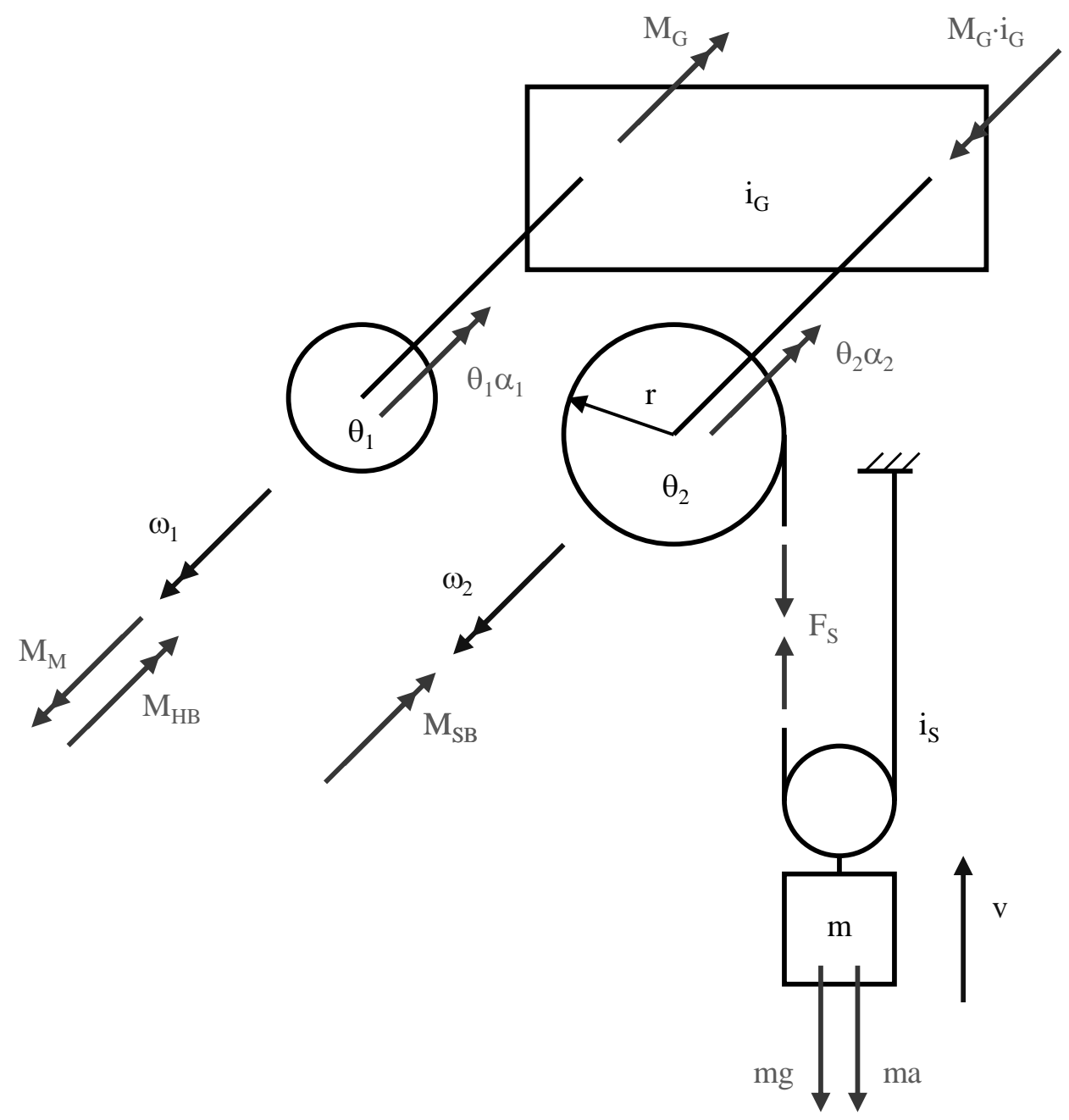

Figure 3: Rigid mass model

Basic for further considerations is the equation for the motor shaft acceleration:

$$
\dot{\omega}_{1}=\frac{M_{M}-M_{H B}-M_{S B}{ }^{*}-L F \cdot M_{S t}{ }^{*}}{\theta_{1}+\theta_{2}{ }^{*}+L F \cdot m^{*}} .
$$

The torque in the gearing input shaft is determined by:

$$
M_{G}=M_{M}-M_{H B}-\theta_{1} \dot{\omega}_{1}
$$

These formulae are valid for all conditions of the systems, either driven or braked down.

In case of braking in emergency cases with the safety brake the torque in the gearing input shaft will reach different levels, depending on given hoisting or lowering modus. Out of hoisting should generally be considered:

$$
\frac{M_{G \max }}{M_{s t}{ }^{*}}=\phi\left(M F\left(L F+B F_{S B}\right)-L F\right)+L F
$$

With full load (load factor LF $=1.0)$ this will lead to

$$
\frac{M_{G \max }}{M_{s t}^{*}}=\phi\left(M F\left(B F_{S B}+1\right)-1\right)+1
$$

With neglecting of dynamic effects (dynamic factor $\phi=1.0)$ this reduces to

$$
\frac{M_{G \max }}{M_{s t}^{*}}=M F\left(B F_{S B}+1\right)
$$

Equivalent equations for braking out of lowering are:

General:

$$
\frac{M_{G \max }}{M_{s t}^{*}}=\phi\left(M F\left(L F-B F_{S B}\right)-L F\right)+L F
$$

Load factor $L F=1.0$ :

$$
\frac{M_{G \max }}{M_{s t}^{*}}=\phi\left(M F\left(1-B F_{S B}\right)-1\right)+1
$$


Dynamic factor $\phi=1.0$ :

$$
\frac{M_{G \max }}{M_{s t}{ }^{*}}=M F\left(1-B F_{S B}\right)
$$

Summarizing, the following general equation can be given:

$$
\frac{M_{G \max }}{M_{s t}{ }^{*}}=\phi\left(M F\left(L F \mp B F_{S B}\right)-L F\right)+L F
$$

\section{+ Hoisting / - Lowering}

Out of these relations high dynamic internal forces may occur. The height of the peaks depends on the base level, the target level and dynamic behaviour (Figure 4). The dynamic behaviour expressed by dynamic factor $\phi$, probably, can not be changed to reduce such peaks. Therefore, conditions are examined to reach the same level for the base level (T1, T2) and the target level (T2, T1).

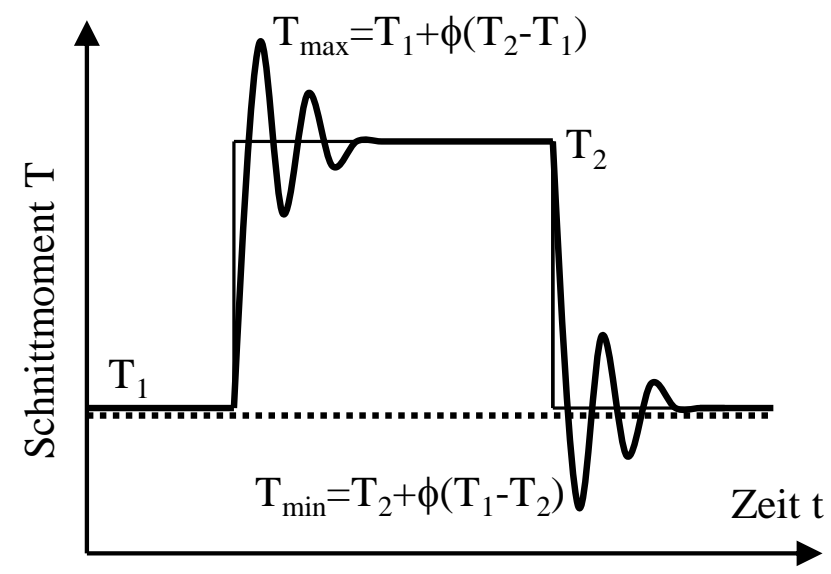

Figure 4: Dynamic loading on input shaft of gearing hoist during braking out of hoisting

The target of the research is to evaluate conditions to have no variation of shaft torque from the moment before braking to the moment just after beginning of braking. These conditions are to be evaluated under the assumption of synchronous activation of holding brake and safety brake.

For hoisting this leads to the following brake factors:

$$
\begin{gathered}
B F_{H B}=-L F-M F \frac{\theta_{g e s}{ }^{*}}{M_{s t}^{*}} \cdot \frac{\Delta \omega}{\Delta t} \\
B F_{S B}=(M F-1) \frac{\theta_{g e s}^{*}}{M_{s t}^{*}} \cdot \frac{\Delta \omega}{\Delta t}
\end{gathered}
$$

Attention: $\Delta \omega$ negative for Braking out of Hoisting

For lowering the results are:

$$
\begin{gathered}
B F_{H B}=L F+M F \frac{\theta_{g e s}^{*}}{M_{s t}^{*}} \cdot \frac{\Delta \omega}{\Delta t} \\
B F_{S B}=(1-M F) \frac{\theta_{g e s}{ }^{*}}{M_{s t}^{*}} \cdot \frac{\Delta \omega}{\Delta t}
\end{gathered}
$$

Attention: $\Delta \omega$ positive for Braking out of Lowering

Summarizing, the following equations for the brake factors can be given:

$$
\begin{gathered}
B F_{H B}=\mp\left(L F+M F \frac{\theta_{g e s}^{*}}{M_{s t}^{*}} \cdot \frac{\Delta \omega}{\Delta t}\right) \\
B F_{S B}=\mp(1-M F) \frac{\theta_{g e s}^{*}}{M_{s t}^{*}} \cdot \frac{\Delta \omega}{\Delta t}
\end{gathered}
$$

Attention: $\Delta \omega$ negative for Braking out of Hoisting, $\Delta \omega$ positive for Braking out of Lowering

The braking factors for the holding brake BFHB, for the safety brake BFSB and the sum of both BFBB+BFSB are shown for hoisting in Figure 5 and for lowering in Figure 6.

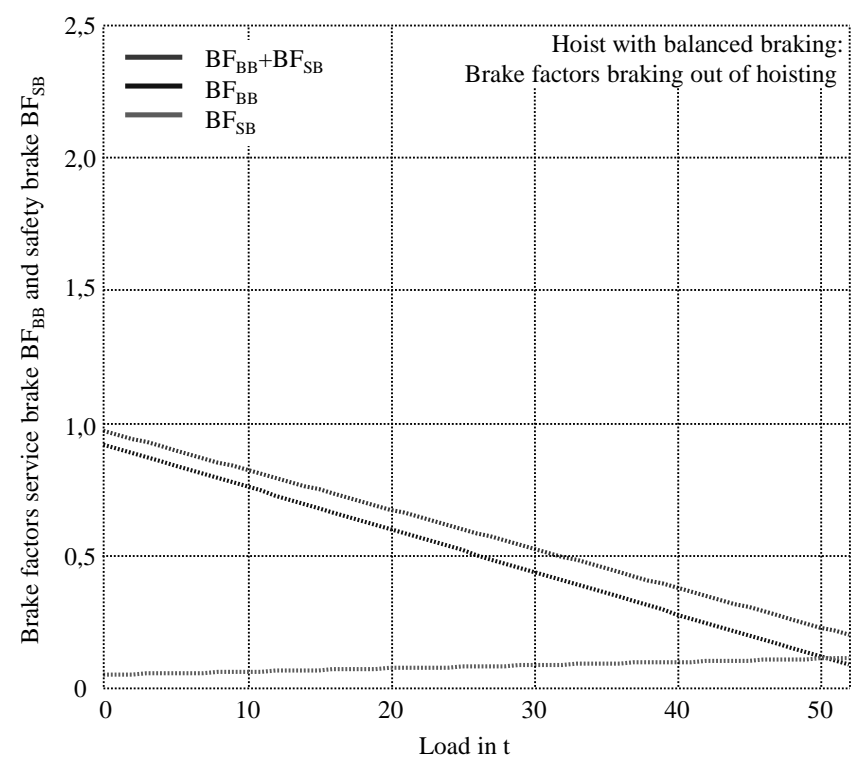

Figure 5: Braking factors for braking out of hoisting 


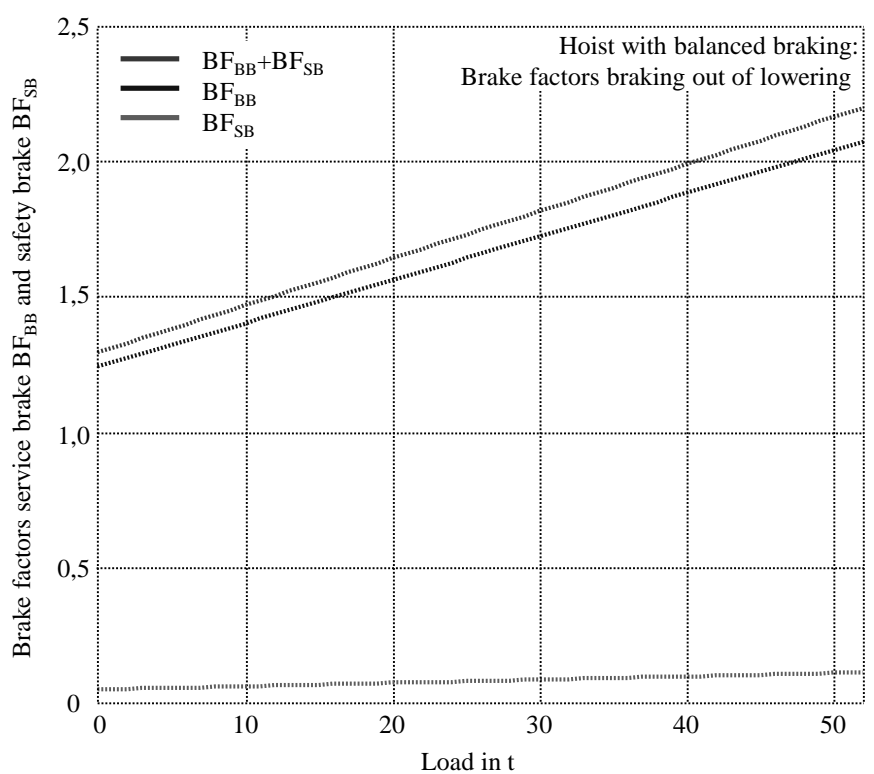

Figure 6: Braking factors for braking out of lowering

\section{RESULTS}

To check the results, the internal torque for the gearing input shaft is considered for different load cases. Compared are the static load torque and the dynamic torque during braking.

Case 1: Hoisting, Dead load, Nominal Speed

$$
\begin{gathered}
L F=\frac{m}{m_{S W L}}=\frac{10 t}{62 t}=0.161 \\
M_{G}=467.4 N m=0.161 M_{s t}^{*}
\end{gathered}
$$

Case 2: Hoisting, Maximum Load, Nominal Speed

$$
\begin{gathered}
L F=\frac{m}{m_{S W L}}=\frac{62 t}{62 t}=1.0 \\
M_{G}=2902.1 \mathrm{Nm}=1.0 M_{s t}^{*}
\end{gathered}
$$

Case 3: Hoisting, Half Load, Nominal Speed

$$
\begin{gathered}
L F=\frac{m}{m_{S W L}}=\frac{31 t}{62 t}=0.5 \\
M_{G}=1453.2 \mathrm{Nm}=0.5 M_{s t}^{*}
\end{gathered}
$$

Case 4: Lowering, Dead load, Nominal Speed

$$
L F=\frac{m}{m_{S W L}}=\frac{10 t}{62 t}=0.161
$$

$$
M_{G}=472.2 N m=0.163 M_{s t}^{*}
$$

Case 5: Lowering, Maximum Load, Nominal Speed

$$
\begin{gathered}
L F=\frac{m}{m_{S W L}}=\frac{62 t}{62 t}=1.0 \\
M_{G}=2889.7 N m=1.0 M_{s t}^{*}
\end{gathered}
$$

Case 6: Lowering, Half Load, Nominal Speed

$$
\begin{gathered}
L F=\frac{m}{m_{S W L}}=\frac{31 t}{62 t}=0.5 \\
M_{G}=1442.8 \mathrm{Nm}=0.5 M_{s t}^{*} .
\end{gathered}
$$

As shown, in all the cases the static load torque and the dynamic torque are equal. If the determined brake factors are applied, no dynamic loading of the gearing input as a result of braking shaft will occur any more. Certainly this insinuates a perfect braking system, which means a braking system with controllable braking torques at all brakes and a synchronous activation of all braking systems. Certainly synchronous activation should take place in a minimum of time [18].

\section{CONCLUSION}

Hoists are dynamic systems with a corresponding dynamic loading of the hoist elements. For safety oriented hoists with brakes on the axis of the motor shaft and on the axis of the rope drum can be shown, that these dynamic loadings can be removed by suitable braking. Synchronous braking with determined torques will prevent the gearing input shaft to be loaded dynamically by braking in theory.

Real systems will have deviations with regard to braking torques [19] and synchrony [20]. It is the task for further work to examine possible real system behavior [21, 22] and the gain remaining due to these variations.

\section{REFERENCES}

[1] Tyulenev M, Zhironkin S., and Litvin O. The low-cost technology of quarry water purifying using the artificial filters of overburden rock. Pollution Research, 2015, vol. 34 (4).: pp 825-830.

[2] Zhironkin S.A. Governmental factoring development of TEK Kuzbass. Ugol', 2001, vol. 6, pp. 62.

[3] Zhironkin S.A. Prospects and new possibilities investment attracting to Kuzbass coal mining industry. Ugol', 2002, vol. 6, pp. 31-36.

[4] Zhironkin S.A. Factoring and leasing development at coal mining industry of Kuzbass as an important element of its financial part. Ugol', 2001, vol. 4, pp. 29-30.

[5] Zhironkin S.A. About measures of vexel circulation development and vexelability definition of fuel-and-power complex' enterprises. Ugol', 2002, vol. 4, pp. 47-48.

[6] Lesin Y.V., Lukyanova S.Y,. and Tyulenev M.A. Mass transfer of dispersed particles in water filtration in macro-grained media. Journal of Mining Science, 2010, vol. 46(1), pp. 78-81.

[7] Lesin Y.V., Luk'yanova S.Y., and Tyulenev M.A. Formation of the composition and properties of dumps on the open-pit mines of 
Kuzbass. IOP Conference Series: Materials Science and Engineering, 2015, vol. 91 (1), 012093

[8] Tyulenev M, Zhironkin S., Kolotov K., and Garina E.. Background of innovative platform for substitution of quarry water purifying technology. Pollution Research, 2016, 35(2), pp. 221-226.

[9] RWTÜV. Schriftenreihe, Heft 8, Krane, Bemessung und Sicherheit. Dresden, 1981, 222 p.

[10] Schmeink M. Dynamische Beanspruchung von Hubwerksgetrieben, Tagungsband 22. Internationale Kranfachtagung, Magdeburg, 2014, pp.211-215.

[11] Khoreshok A. On side cutting bit when operating at sheerer drums. Ugol', 2002, vol. 7, pp. 10-11.

[12] Aksenov V.V., Khoreshok A.A., and Beglyakov V.Yu. Justification of creation of an external propulsor for multipurpose shield-type heading machine - GEO-WALKER. Applied Mechanics and Materials, 2013, vol. 379, pp. 20-23.

[13] Tyulenev M.A., and Lesin Y.V. Justification complex purification technology open-pit mines wastewater. Taishan: Academic Forum Project on Mine Disaster Prevention and Control, 2014, pp. 441444.

[14] Kovalev V., Gerike B., Khoreshok A., and Gerike P. Preventive Maintenance of Mining Equipment Based on Identification of Its Actual Technical State. Taishan Academic Forum - Project on Mine Disaster Prevention and Control, 2014, pp. 184-189.

[15] Tyulenev M, Zhironkin S. and Litvin O. The low-cost technology of quarry water purifying using the artificial filters of overburden rock. Pollution Research, 2015, vol. 34 (4). pp. 825-830
[16] DIN (Hrsg.). DIN EN 13001-2: Crane safety, General design, Part 2: Load actions, DIN Deutsches Institut für Normung e.V., Beuth Verlag, 2014, $34 \mathrm{p}$

[17] Vöth S., and Tyulenev M. Pod'emnye mashiny s tormozami bezopasnosti [Hoists with safety brakes]. Vestnik Kuzbasskogo gosudarstvennogo tehnicheskogo universiteta, 2016, vol. 1(113), pp. 88-97.

[18] Römer R. Electrohydraulic lifting device and method for controlling said electrohydraulic lifting device, Patent WO 2014/005839 A1, 2013.

[19]Römer R. Difference between dynamic and static coefficient of friction, Port Technology International, 56th Edition, Winter 2012, pp. 49-51.

[20] Vöth S. Safety Systems for Container Cranes, 17th ITI Symposium, Dresden. 2014, pp. 144-151.

[21] Melchers K., Kretschmann Yu., Goerke-Mallet P., Kleineberg K., and Tyulenev M. Elementy i aspekty post-ekspluatatsionnogo perioda gornykh predpriyatij [Elements and aspects of postoperational period of mining enterprizes]. Vestnik Kuzbasskogo gosudarstvennogo tehnicheskogo universiteta, 2015, vol. 6, pp. 3 13.

[22] Prokopenko S.A. Multiple service life extension of mining and road machines' cutters. Applied Mechanics and Materials, 2014, vol 682, pp. 319-323. 